\title{
El control de barreras burocráticas por el INDECOPI y la tutela de derechos fundamentales económicos
}

\section{INDECOPI's bureaucratic barriers control and economic fundamental rights guardianship}

\section{CÉSAR OCHOA CARDICH*}

Resumen: En el presente estudio se analiza el rol de tutela de los derechos fundamentales de libertad de empresa, no discriminación económica y de propiedad ejercido por la Comisión de Eliminación de Barreras Burocráticas del Instituto Nacional de Defensa de la Competencia y de la Protección de la Propiedad Intelectual - INDECOPI—, que se ha desarrollado a través de sus resoluciones y de los precedentes administrativos establecidos por la Sala de Defensa de la Competencia 1.

Este rol de tutela es muy relevante en nuestro sistema jurídico, en el cual, por su especialidad funcional, la Comisión de Eliminación de Barreras Burocráticas está habilitada por mandato legal para la inaplicación de normas en casos concretos en ejercicio del control de legalidad.

Esta función administrativa - que en sus inicios fue incomprendida- ha resultado una herramienta eficaz para la tutela de los derechos económicos del administrado en razón de la inoperancia del sistema judicialista en lo contencioso administrativo en el Perú.

El autor considera que debe estudiarse la posibilidad de reformar la Constitución para atribuir a ciertos órganos administrativos especializados, como los del INDECOPI, la calidad de jurisdicción administrativa primaria, cuyas resoluciones solo serán revisables por la jurisdicción de un Consejo de Estado.

Palabras clave: barrera burocrática - derecho de igualdad - libertad de empresa - derechos fundamentales económicos

Summary: This study analyzes the guardianship role on entrepreneurial freedom fundamental rights, non- discrimination in economic and property aspects exerted by the Elimination of Bureaucratic Barriers Commission from the National Institute for the Defense of Competition and Intellectual Property (INDECOPI) developed throughout resolutions and administrative cases set up by the Defense of Competition Chamber \#1. This role is particularly relevant in our legal system, due to their special functions the Elimination of Bureaucratic Barriers Commission is entitled by legal mandate

\footnotetext{
* Profesor de Derecho Administrativo del Departamento de Derecho de la Pontificia Universidad Católica del Perú. El autor agradece la participación de los profesores Eduardo Quintana, Alberto Cairampoma y Francisco Ruiz de Castilla por sus sugerencias en el coloquio realizado el día 6 de junio de 2013. Correo electrónico: cochoa@amprimoabogados.com, 
to establish the non- application of rules in specific cases exercising legal control. This administrative function- initially misunderstood-has proved to be an efficient tool for the guardianship of economic rights due to our judicial system ineffectiveness in contentious administrative matters. The author considers the possibility of making a constitutional reform in order to provide specialized administrative bodies, such as INDECOPI, with the quality of "primary administrative jurisdiction" whose resolutions will only be reviewed by the State Council jurisdiction.

Key words: bureaucratic barrier - right to equality - entrepreneurial liberty economic fundamental rights

\begin{abstract}
CONTENIDO: I. A MODO DE INTRODUCCIÓN.- II. EL CONCEPTO DE BARRERA BUROCRÁTICA IRRACIONAL E ILEGAL Y LA PROTECCIÓN JURÍDICA DE LA LIBERTAD DE EMPRESA.- III. EL CONCEPTO DE BARRERA BUROCRÁTICA Y EL DERECHO DE IGUALDAD Y NO DISCRIMINACIÓN ECONÓMICA.- IV. EL CONCEPTO DE BARRERA BUROCRÁTICA Y LA TUTELA DEL DERECHO DE PROPIEDAD EN LA REVOCACIÓN DE LICENCIAS.- V. CONCLUSIONES.
\end{abstract}

\title{
I. A MODO DE INTRODUCCIÓN
}

Empezamos este trabajo citando al destacado constitucionalista alemán Konrad Hesse, quien afirma que el derecho constitucional asume incluso la función de guía, pionero y conductor de una nueva configuración del derecho ${ }^{1}$.

Este rol del derecho constitucional se ha ido perfilando y consolidando en el Perú, particularmente en el ámbito del derecho público. Así, si bien se reconoce ampliamente en la doctrina alemana que el derecho administrativo es un derecho constitucional concretado ${ }^{2}$, esta concepción no ha imperado sino hasta tiempos recientes en nuestro sistema jurídico. Más bien se podría afirmar que en el Perú se dio una relación entre el derecho administrativo y el derecho constitucional similar a la producida en Alemania entre el derecho privado y el derecho constitucional. En la práctica, durante el siglo XX el derecho administrativo era el derecho de la función administrativa del Estado y ejercía una primacía material frente al derecho constitucional. Así, como sostenía el administrativista alemán Otto Mayer en 1904 sobre el derecho administrativo en la época del Reich (1871-1918):

La Constitución no basta para hacer actuar el Estado: este necesita, por debajo de los poderes constituidos, otros instrumentos para su

1 HeSSSE, Konrad. Derecho constitucional y derecho privado. Madrid: Civitas, 1995, p. 34.

2 Desde el inicio de la República Federal de Alemania, en la década de 1950, es un concepto que describe la relación entre el derecho constitucional y el derecho administrativo. 
acción, las autoridades, los servicios públicos, los cargos de toda clase se crean para obrar, sea en nombre del Estado, sea en nombre de una persona jurídica secundaria, de un cuerpo de administración propia (Selbstwaltungskórper) $^{3}$.

Esta situación cambia con la Ley Fundamental de Bonn de 1949, que afirma el carácter vinculante de los derechos fundamentales como normas jurídicas generales. Sobre la primacía del derecho constitucional, Ibler señala que:

Hoy en día, rige la jerarquía normativa evidente entre los derechos fundamentales de la Ley Fundamental con respecto a las leyes y las demás manifestaciones del actuar estatal. La Ley Fundamental tiene rango superior y constituye la medida para la ley y para todas las demás acciones estatales. Las leyes solo están en vigor si son conformes con la Ley Fundamental. Las actuaciones administrativas y de la jurisprudencia contencioso-administrativa que estén en contradicción con los derechos fundamentales son contrarias a derecho, pues todo el derecho administrativo tiene que ser conforme a estos ${ }^{4}$.

Sobre el rol del Tribunal Constitucional alemán respecto de la relación entre el derecho constitucional y el derecho administrativo, Ibler enfatiza que progresivamente el Supremo Tribunal ha interpretado los derechos fundamentales de forma tan expansiva que en la práctica toda actuación del Estado en el ejercicio de la función administrativa puede rozar el ámbito de protección de un derecho fundamental. Así ejemplifica esta afirmación:

Por ejemplo, se considera afectado el derecho fundamental a la libertad general de acción del art. 2, párr. $1 \mathrm{LF}$ y por ello se admite un recurso de amparo, si una ley prohíbe al ciudadano cabalgar en el bosque (BVerfGE, t. 80, p. 137 y ss.), o si una administración municipal prohíbe dar comida a las palomas en los parques, aunque los tribunales lo hayan considerado legítimo (BVerfGE, t. 54, p. 143 y ss.) $)^{5}$.

En el Perú, hemos padecido un derecho administrativo propio de una República sin ciudadanos —como llamó Flores Galindo al inicio de la República- Ese derecho administrativo ha estado parcialmente vigente hasta los albores del siglo XXI con la entrada en vigor el año 2001 de la ley 27444, Ley del Procedimiento Administrativo General, que se puede considerar como la primera norma garantista de procedimiento

3 MAYER, Otto. Derecho administrativo alemán. Tomo I. Buenos Aires: Depalma, 1982, p. 18. El original francés se tituló: Le droit administratif allemand.

4 IBLER, Martin (2010) "Derecho administrativo como derecho constitucional concretizado». Res Publica, 2 (2010), Bogotá, p. 40.

5 lbíd., p. 43.

EL CONTROL

DE BARRERAS

BUROCRÁTICAS

POR EL INDECOPI

Y LA TUTELA

DE DERECHOS

FUNDAMENTALES

ECONÓMICOS

INDECOPI'S

BUREAUCRATIC

BARRIERS

CONTROL AND

ECONOMIC

FUNDAMENTAL

RIGHTS

GUARDIANSHIP 
administrativo en el Perú en la que se regula la tutela de los derechos fundamentales del ciudadano frente a la administración.

César Landa destaca que la fuerza normativa de la Constitución ha encontrado en la tutela de los derechos fundamentales, y en la garantía de la supremacía de la Constitución, el fundamento tanto de su institucionalización como de su funcionamiento gracias a la jurisdicción constitucional, ya sea en sede ordinaria o en sede del Tribunal Constitucional ${ }^{6}$. En esa misma dirección, se puede citar en la jurisprudencia constitucional peruana a la STC 3741-2004-AA/ TC recaída en el caso «Ramón Hernando Salazar Yarlenque». En esa sentencia, el supremo intérprete de la Constitución estableció un precedente sobre el control difuso de constitucionalidad en sede administrativa. Afirmó en el fundamento jurídico 11 sobre el control de constitucionalidad y legalidad de los actos de la administración que:

Esta incidencia de los derechos fundamentales en el Estado constitucional implica, por otra parte, un redimensionamiento del antiguo principio de legalidad en sede administrativa, forjado en el siglo XIX en una etapa propia del Estado liberal. Si antes la eficacia y el respeto de los derechos fundamentales se realizaba en el ámbito de la ley, en el Estado constitucional, la legitimidad de las leyes se evalúa en función de su conformidad con la Constitución y los derechos fundamentales que ella reconoce. Por eso mismo, es pertinente señalar que el derecho y el deber de los tribunales administrativos y órganos colegiados de preferir la Constitución a la ley, es decir de realizar el control difuso — dimensión objetiva -, forma parte del contenido constitucional protegido del derecho fundamental del administrado al debido proceso y la tutela procesal ante los tribunales administrativo —dimensión subjetiva(cursiva nuestra).

Así, el Tribunal Constitucional peruano reconoció primacía al principio de supremacía constitucional y de fuerza normativa de la Constitución sobre el principio de legalidad?

Se debe destacar que, antes del surgimiento de la doctrina jurisprudencial sobre el rol de los tribunales administrativos, en materia de tutela de los derechos fundamentales económicos cumplió un rol pionero el Instituto Nacional de Defensa de la Competencia y de la Protección

6 LANDA, César. Justicia constitucional y derechos fundamentales. Fuerza normativa de la Constitución. Uruguay: Universidad de Chile y Konrad Adenauer-Stiftung E.V., 2011, p. 41.

7 A favor de esa doctrina jurisprudencial véase a: DEL POzo, Claudia. Control difuso y procedimiento administrativo. Lima: Palestra, 2005; KU YANASUPO, Lily. «El control difuso en sede administrativa. ¿Los tribunales administrativos protegen los derechos fundamentales?». Revista Jurídica del Perú, 132 (2012), pp. 25-43. En sentido contrario, CASTILLO CóRDOVA, Luis. «Administración pública y control de la constitucionalidad de las leyes». En O. Vignolo y R. Jiménez (coords.). Homenaje a Allan Brewer Carías. Lima: Ediciones Legales E.I. R. L. y Asociación Civil lus Et Veritas, 2012, pp. 381 a 414. 
de la Propiedad Intelectual (INDECOPI), creado en noviembre de 1992 por el decreto ley 25868, en el período de Poder Ejecutivo de facto del régimen de Alberto Fujimori Fujimori (1990-2000).

Es así que durante el régimen de Fujimori — de radical privatización y apertura de la economía peruana - en materia de tutela del derecho fundamental de la libertad de empresa se dicta una disposición legal que debemos reconocer de avanzada: es el artículo 26 bis del decreto ley 25868 incorporado por el artículo 50 del decreto legislativo 807, publicado el 18 de abril de 1996. Esta disposición estableció que:

Artículo 26 BIS.- La Comisión de Acceso al Mercado es competente para conocer sobre los actos y disposiciones de las entidades de la administración pública, incluso del ámbito municipal o regional, que impongan barreras burocráticas que impidan u obstaculicen ilegal o irracionalmente el acceso o permanencia de los agentes económicos en el mercado, en especial de las pequeñas empresas, y de velar por el cumplimiento de las disposiciones sobre la materia establecidas en los decretos legislativos № 283, 668, 757, el artículo 61 del decreto legislativo 776 y la ley 25035, en especial los principios generales de simplificación administrativa contenidos en su artículo 2, así como las normas reglamentarias pertinentes. Ninguna otra entidad de la administración pública podrá arrogarse estas facultades. La Comisión, mediante resolución, podrá eliminar las barreras burocráticas a que se refiere este artículo.

La Comisión podrá imponer sanciones y multas al funcionario o funcionarios que impongan la barrera burocrática declarada ilegal, sin perjuicio de la responsabilidad administrativa y la formulación de la denuncia penal correspondiente de ser el caso. La escala de sanciones es la siguiente: falta leve con amonestación; falta grave con multa de hasta dos UIT y falta muy grave con multa de hasta cinco UIT.

En caso que la presunta barrera burocrática haya sido establecida en un decreto supremo o resolución ministerial, la Comisión no podrá ordenar su derogatoria o implicación ni imponer sanciones. En tal supuesto el pronunciamiento de la Comisión se realizará a través de un informe que será elevado a la Presidencia del Consejo de Ministros para ser puesto en conocimiento del Consejo de Ministros a fin de que este adopte las medidas que correspondan.

El artículo 48 de la ley 27444 -modificado por el artículo 3 de la ley 28996 - Ley de Eliminación de Sobrecostos, Trabas y Restricciones a la Inversión Privada, publicada en el diario oficial El Peruano el 4 de abril de 2007, prevé que cuando en un asunto de competencia de la Comisión de Acceso al Mercado la barrera burocrática haya sido establecida por un decreto supremo, una resolución ministerial o una norma municipal o regional de carácter general, dicha Comisión se pronunciará mediante

EL CONTROL DE BARRERAS BUROCRÁTICAS POR EL INDECOPI Y LA TUTELA DE DERECHOS FUNDAMENTALES ECONÓMICOS

INDECOPI'S BUREAUCRATIC BARRIERS CONTROL AND ECONOMIC FUNDAMENTAL RIGHTS GUARDIANSHIP 
resolución, ejerciendo el control difuso de legalidad en el caso concreto. La resolución de la Comisión podrá ser impugnada ante la Sala de Defensa de la Competencia del Tribunal de Defensa de la Competencia y de la Propiedad Intelectual del INDECOPI. El precitado artículo modificado establece que:

[...] Cuando en un asunto de competencia de la Comisión de Acceso al Mercado la barrera burocrática haya sido establecida por un decreto supremo, una resolución ministerial o una norma regional de carácter general, dicha Comisión se pronunciará, disponiendo su inaplicación al caso concreto. La resolución de la Comisión podrá ser impugnada ante la Sala de Defensa de la Competencia del Tribunal de Defensa de la Competencia y de la Propiedad Intelectual del INDECOPI.

Sin perjuicio de la inaplicación al caso concreto, la resolución será notificada a la entidad estatal que emitió la norma para que pueda disponer su modificación o derogación.

Asimismo, tratándose de procedimientos iniciados de oficio por la Comisión de Acceso al Mercado, el INDECOPI podrá interponer demanda de acción popular contra barreras burocráticas contenidas en decretos supremos con el fin de lograr su modificación o derogación y, con el mismo propósito, acudir a la Defensoría del Pueblo para que se interponga la demanda de inconstitucionalidad contra barreras burocráticas contenidas en normas municipales y regionales de carácter general que tengan rango de ley [...] (cursiva nuestra).

En el año 2009, el alcalde de la Municipalidad Metropolitana de Lima, Luis Castañeda Lossio, interpuso una demanda de inconstitucionalidad contra el artículo 3 de la ley 28996 que modificó el precitado artículo 48 de la ley 27444, mediante el cual se habilitaba a la Comisión de Acceso al Mercado a inaplicar normas en los asuntos de su competencia. La demanda sostenía que se vulneraba el artículo 138 de la Constitución referido al control difuso, los principios de supremacía de la Constitución, de competencia y separación de poderes, así como las normas constitucionales referidas a la autonomía y competencia de los gobiernos locales.

En la sentencia recaída en el expediente 0014-2009-PI/TC, expedida el 25 de agosto de 2010, el Tribunal Constitucional se pronunció sobre el ejercicio de la inaplicación de una norma jurídica al caso concreto por la Comisión de Eliminación de Barreras Burocráticas —antes Comisión de Acceso al Mercado- como un control de legalidad como competencia propia de una entidad del Poder Ejecutivo. Así, en los fundamentos 25 y 26 precisó:

Sin perjuicio de lo anotado, en este caso este Colegiado debe puntualizar, a partir de lo expresado en los fundamentos anteriores, 
que cuando la $\mathrm{CEB}$ «inaplica» una ordenanza, formalmente no alega su inconstitucionalidad sino su ilegalidad. Por ejemplo, cuando en un procedimiento administrativo se detecta que una ordenanza es contraria a normas, como el decreto legislativo № 757 (Ley Marco para el Crecimiento de la Inversión Privada), ley № 27444, ley № 28976 (Ley Marco de Licencia de Funcionamiento) e inclusive la ley № 27972 (Ley Orgánica de Municipalidades), la CEB resuelve tal antinomia en virtud del principio competencia excluyente, "aplicable cuando un órgano con facultades legislativas regula un ámbito material de validez, el cual, por mandato expreso de la Constitución o una ley orgánica, comprende única y exclusivamente a dicho ente legisferante" [0047-2004-AI/T, fund. 54, e)]. Como se observa, la situación generada se resuelve a partir de determinar que se trata de una antinomia entre dos normas del mismo rango, como pueden ser las leyes formales y las ordenanzas regionales y municipales. Su resolución descansa, por consiguiente, en la aplicación de la norma legal aplicable al caso concreto, en virtud de competencias repartidas y no en virtud de un análisis de jerarquía entre ordenanza (regional o local) y la Constitución (fundamento jurídico 25).

El ejercicio de la CEB se circunscribe al ámbito de protección de la competitividad del mercado, tarea que, en virtud de la unidad del mercado, está bajo la competencia del Ejecutivo, que vigilará la preservación del orden público económico. Así, no resulta argumentable que en ejercicio de la autonomía municipal y regional se contravengan normas de alcance nacional, como por ejemplo la Ley del Procedimiento Administrativo General o la Ley Marco de Licencia de Funcionamiento, en virtud de una ordenanza municipal o regional (fundamento jurídico 26, cursiva nuestra).

En esa dirección, el Tribunal Constitucional del Perú ratificó la doctrina jurisprudencial de supremacía de la Constitución sobre el principio de legalidad sustentada en el caso "Ramón Hernando Salazar Yarlenque», aun cuando el caso en cuestión estaba referido al control difuso de legalidad y no al control difuso de constitucionalidad. Asimismo, en esta sentencia precisó que el reconocimiento del control difuso de legalidad no suponía que se hubiese derogado el control judicial mediante el proceso contencioso- administrativo. En el fundamento jurídico 32 se puntualizó que:

Debe recordarse, finalmente, que si bien la inaplicación de una disposición a un caso concreto en sede administrativa carece de un mecanismo de consulta a un órgano administrativo jerárquicamente superior, no quiere ello decir que sus decisiones no pueden cuestionarse. La posibilidad de que el administrado pueda recurrir a la vía judicial correspondiente para impugnar las decisiones de los tribunales 
administrativos está siempre abierta de acuerdo con el artículo 148 de la Constitución ${ }^{8}$.

En ese sentido, consideramos que se ha producido una mutación constitucional, por cuanto el sistema de justicia en nuestra Constitución histórica y hasta la actualidad ha sido estrictamente judicialista, prohibiendo al Poder Ejecutivo el ejercicio de funciones judiciales siguiendo la huella de la Constitución de Cádiz de 1812. Así, la Norma Suprema establece lo siguiente:

Artículo 139.- Principios de la Administración de Justicia.

Son principios y derechos de la función jurisdiccional.

1. La unidad y exclusividad de la función jurisdiccional.

No existe ni puede establecerse jurisdicción alguna independiente, con excepción de la militar y la arbitral.

2. La independencia en el ejercicio de la función jurisdiccional. Ninguna autoridad puede avocarse a causas pendientes ante el órgano jurisdiccional ni interferir en el ejercicio de sus funciones. Tampoco puede dejar sin efecto resoluciones que han pasado en autoridad de cosa juzgada, ni cortar procedimientos en trámite, ni modificar sentencias ni retardar su ejecución [...].

Cassagne $^{9}$ distingue en Hispanoamérica dos estructuras de los sistemas de justicia administrativa:

(i) La configuración o no de un fuero especializado (tribunal judicial en lo contencioso administrativo) para conocer los litigios en los que es parte la administración pública o, en general, donde se debatan cuestiones regidas por el derecho administrativo.

(ii) El reconocimiento limitado de ciertas funciones jurisdiccionales a órganos de la administración pública, si bien sobre la base del principio de control judicial suficiente, que exige que, en estos casos, dicho control sea pleno, con amplitud de debate y prueba.

En esa dirección, podemos afirmar que, a partir de la doctrina jurisprudencial del Tribunal Constitucional sobre el control difuso en sede administrativa, el sistema de justicia administrativa peruano, además de contar con un fuero especializado judicial en lo contencioso administrativo, reconoce limitadamente funciones jurisdiccionales a los tribunales administrativos que tengan por finalidad la declaración de derechos fundamentales de los administrados, como es el caso de la

8 El artículo 148 de la Constitución Política del Perú establece: «Las resoluciones administrativas que causan estado son susceptibles de impugnación mediante la acción contencioso administrativa».

9 CASSAgne, Juan Carlos y J. GonzÁLEz PéREZ. La justicia administrativa en Iberoamérica. Buenos Aires: Lexis Nexis, 2005, pp. 32-33. 
Comisión de Eliminación de Barreras Burocráticas y la Sala de Defensa de la Competencia 1 del INDECOPI.

El decreto legislativo 1033, decreto legislativo que aprueba la Ley de Organización y Funciones del Instituto Nacional de Defensa de la Competencia y de la Protección de la Propiedad Intelectual, publicado el 25 de junio de 2008, define en su artículo 1 al INDECOPI como un organismo público especializado, con personería jurídica de derecho público interno, que goza de autonomía funcional, técnica, económica, presupuestal y administrativa. Se encuentra adscrito a la Presidencia del Consejo de Ministros.

En el literal a) del numeral 2.1 del artículo 2 se prevé como función administrativa del INDECOPI:

Vigilar la libre iniciativa privada y la libertad de empresa mediante el control posterior y eliminación de las barreras burocráticas ilegales e irracionales que afectan a los ciudadanos y empresas, así como velar por el cumplimiento de las normas y principios de simplificación administrativa.

En el presente estudio nos centraremos en el rol del INDECOPI sobre el control de barreras burocráticas y su tutela de los derechos económicos fundamentales.

\section{EL CONCEPTO DE BARRERA BUROCRÁTICA IRRACIONAL E ILEGAL Y LA PROTECCIÓN JURÍDICA DE LA LIBERTAD DE EMPRESA}

Se afirma que el concepto de barrera burocrática alude a límites arbitrarios o injustificados impuestos por el Estado que impiden el acceso o la permanencia en el mercado ${ }^{10}$. En la actualidad predomina una connotación peyorativa de la burocratización. Así, según el Diccionario de la Real Academia Española, en una de sus acepciones burocracia significa: «administración ineficiente a causa del papeleo, la rigidez y las formalidades superfluas».

En la sociología se ha desarrollado una definición de la burocracia como organización. A este respecto, hay que reconocer que el concepto de organización es polisémico. Hasta la mafia es una organización con jerarquía, estructura y códigos de honor.

El eminente sociólogo alemán Max Weber dedicó al estudio de la organización burocrática un capítulo en su libro Economía y sociedad ${ }^{11}$. 
En su texto «iQué es la burocracia?», Weber afirmaba que esta organización tiene un carácter racional determinado por normas, medios, fines y situaciones de hecho. Así, la burocratización es un término con una connotación positiva basada en la posibilidad óptima de poner en práctica el principio de especialización de las funciones administrativas conforme a regulaciones estrictamente objetivas ${ }^{12}$.

En términos económicos debe destacarse el estudio de Mínguez, basado en la amplia literatura sobre el tema. Sostiene que el cumplimiento de trámites derivados de la regulación impacta con un costo directo para ciudadanos y empresas. Asimismo, la regulación administrativa puede generar barreras que desincentiven a los agentes económicos a participar en los mercados o disminuir la competencia existente con efecto perjudicial para los consumidores en términos de precios, variedad o relación calidad-precio ${ }^{13}$.

Karlson sostiene —desde la perspectiva eminentemente teóricaque una economía con una regulación escasa experimenta mejoras en términos de eficiencia, crecimiento y empleo hasta determinado punto óptimo, más allá del cual todo incremento en el número de normas genera un alejamiento de dicho óptimo ${ }^{14}$.

El siguiente gráfico de Karlson, denominado «Curva de la Regulación», describe sus efectos en términos de eficiencia, empleo y crecimiento.

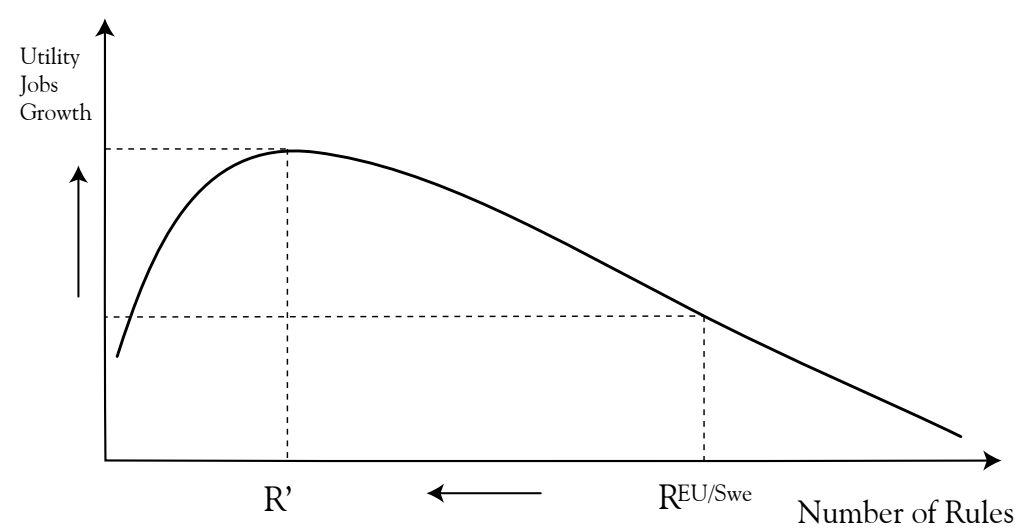

12 Véase el texto de Weber en: <http://www.ucema.edu.ar/u/ame/Weber_burocracia-pdf>.

13 Véase el documento publicado en julio de 2011 «Estudio de medición de impacto de las barreras burocráticas en el mercado», p. 6, en: <http://www.indecopi.gob.pe>.

14 KARLSON, N. (2009). Effects of regulations on Economic Performance: Is there a link? A critical view, citado en: «Estudio de medición de impacto de las barreras burocráticas en el mercado», cit., p. 11. 
En términos jurídicos, se debe entender que el concepto de barrera burocrática constituye una afectación arbitraria y desproporcionada al contenido esencial del derecho de la libertad de empresa previsto en el artículo 58 de la Constitución, que asumimos como un derecho fundamenta ${ }^{15}$. El mencionado artículo declara que:

La iniciativa privada es libre. Se ejerce en una economía social de mercado. Bajo este régimen, el Estado orienta el desarrollo del país, y actúa principalmente en las áreas de promoción de empleo, salud, educación, seguridad, servicios públicos e infraestructura.

Al determinar el contenido esencial de la libertad de empresa, la doctrina ${ }^{16}$ señala como ámbitos o aspectos esenciales:

(i) La libertad de creación de empresa y su acceso al mercado.

(ii) La libertad de organización.

(iii) La libertad de competencia.

(iv) La libertad para cesar sus actividades.

Estas cuatro libertades han sido reconocidas en nuestra jurisprudencia constitucional en el fundamento jurídico 13 de la sentencia recaída en el expediente 3330-2004-AA/TC, correspondiente al caso «Ludesminio Loja Mora», pronunciada el 11 de julio de $2007^{17}$.

En el texto anterior me he inclinado por asumir la teoría relativa del contenido esencial de los derechos fundamentales. Así, he sostenido que en el derecho fundamental de la libertad de empresa no existe ningún reducto en su contenido que pueda ser indisponible para el legislador, de modo que se podrá afectar, intervenir y sacrificar el contenido del derecho fundamental, siempre y cuando se aplique correctamente el principio de proporcionalidad ${ }^{18}$.

Asimismo, la forma de actuación de ordenación de la administración pública puede afectar legítimamente el contenido esencial de la libertad de empresa. La ordenación — tradicionalmente denominada como

15 KresalJa, B. y OCHOA, C. Derecho constitucional económico. Lima: Fondo Editorial de la Pontificia Universidad Católica del Perú, 2009, pp. 450 y ss.

16 ARIÑO, Gaspar. Principios de derecho público económico. Lima: Universidad Externado de Colombia/ Fundación de Estudios de Regulación, 2003, pp. 264 y ss; KRESALJA, B. y OCHOA, C. Ob. cit., pp. 451 y ss.

17 Se trató de un proceso de amparo mediante el cual el demandante pretendía que se deje sin efecto resoluciones de alcaldía que se pronunciaban por la nulidad de una resolución de alcaldía que ordenaba la prosecución del trámite de autorización de funcionamiento de una discoteca.

18 OCHOA, César. «Fundamentos y límites constitucionales de la libertad de empresa». Gaceta Constitucional, 21(2009), pp. 70-71. En esa dirección, coincidimos con BERNAL PULIDO, Carlos. El principio de proporcionalidad y los derechos fundamentales. Madrid: Centro de Estudios Constitucionales, 2003, p. 486: «El resultado de este detallado análisis hace pensar que en el estadio actual de evolución del pensamiento jurídico constitucional; la aplicación del principio de proporcionalidad se proyecta como el método más ventajoso para el control de las leyes de intervención en los derechos fundamentales y para la definición de los contenidos vinculantes que se derivan de tales derechos».

EL CONTROL

DE BARRERAS

BUROCRÁTICAS

POR EL INDECOPI

Y LA TUTELA

DE DERECHOS

FUNDAMENTALES

ECONÓMICOS

INDECOPI'S

BUREAUCRATIC

BARRIERS

CONTROL AND

ECONOMIC

FUNDAMENTAL

RIGHTS

GUARDIANSHIP 
poder de policía - se ejerce en actividades que pueden impactar en el interés general pero que son de libre iniciativa privada. Como precisa Santamaría Pastor, son actividades que potencialmente pueden lesionar el interés público:

La mayor parte, sin embargo, son actividades que poseen una potencialidad lesiva para el interés general; por ello, la administración las somete a ordenación, planificación, organización, dirección, limitación, control u orientación: las condiciona, en una palabra, con el fin de evitar que produzcan perjuicio al interés general. Toda esa labor de condicionamiento de las conductas privadas es, precisamente, el contenido de la actividad administrativa de ordenación ${ }^{19}$.

El mencionado autor desarrolla los principios del régimen jurídico de las técnicas de ordenación:

- Los principios de carácter formal: (i) El principio de reserva de ley: cualesquiera supuestos de intervención, limitación o ablación de la libertad de los ciudadanos debe legitimarse necesariamente en una habilitación conferida en normas con rango de ley. (ii) $E l$ principio de especificación: las previsiones legislativas de poderes de intervención han de ser tasadas y singularizadas respecto de categorías de supuestos de hecho claramente individualizadas. No cabe el establecimiento por vía normativa de poderes generales de intervención, ni con carácter general ni de alcance sectorial. Estas normas deben interpretarse con una eficacia meramente descriptiva e interpretativa del ámbito de acción de las potestades concretas que, en todo caso, deben establecerse.

- Los principios de carácter material: (i) El principio de proporcionalidad: implica una exigencia de adecuación cuantitativa entre la finalidad que debe perseguir la técnica de ordenación que se establezca y el diseño concreto de las facultades que la integren. Es un principio que veta la atribución de poderes materialmente innecesarios para lograr los fines concretos que persigue la intervención que se impone. (ii) El principio pro libertate: según este principio, cuando la norma que establece la potestad de intervención puede razonablemente optar entre varias medidas alternativas para conseguir su finalidad ordenadora, debe necesariamente elegir la que resulte menos restrictiva de la libertad individual de los sujetos sobre los que vaya a ser empleada ${ }^{20}$. 
Conforme a la doctrina y la jurisprudencia, la libertad de empresa como derecho fundamental se ejerce tanto en la entrada al mercado como en su continuidad y estabilidad, porque se protege a todo el ciclo. La libertad de empresa es la base del sistema económico constitucionalizado, de la economía social de mercado, y a su vez, es el soporte de otras libertades fundamentales.

La libertad de creación de empresas y de acceso al mercado es el derecho de emprender actividades económicas en el sentido de libre fundación de empresas y de concurrencia en el mercado. Así, cualquier persona que reúna los requisitos legales necesarios puede crear empresas y tiene derecho de establecimiento en cualquier sector económico, sin que se admitan prohibiciones o autorizaciones puramente discrecionales de la administración ${ }^{21}$.

Es importante destacar que, durante la vigencia de la Constitución de 1979, se dictó en noviembre de 1991 el decreto legislativo 757, Ley Marco para el Crecimiento de la Inversión Privada, que en su artículo 3 define a la libre iniciativa privada en los siguientes términos:

Se entiende por libre iniciativa privada el derecho que tiene toda persona natural o jurídica a dedicarse a la actividad económica de su preferencia, que comprende la producción o comercialización de bienes o la prestación de servicios, en concordancia con lo establecido por la Constitución, los tratados internacionales suscritos por el Perú y las leyes.

Asimismo, se debe tener presente que el artículo 59 de la Constitución de 1993 declara que se garantiza la libertad de comercio e industria, dentro de los límites de la moral, la salud y la seguridad pública. La Constitución de 1993 explicita en esta disposición una manifestación de inspiración liberal sobre la intervención del Estado dentro de la concepción clásica del poder de policía ${ }^{22}$.

Sin perjuicio de ello, cabe señalar que en el área de servicios públicos económicos, cuya titularidad corresponde el Estado, el acto de declaración - publicatio - de una actividad o de un sector como «público» o como «servicio público» significa que tal actividad queda incorporada al quehacer del Estado y excluida de la esfera de actuación de los particulares, aunque pueda darse a estos en concesión. En consecuencia, no existe una libertad de acceso al mercado. Con relación a las regulaciones propias del régimen de un servicio público no consideramos que sea aplicable el concepto de barrera burocrática de acceso al mercado. El mercado es institución propia del orden 
socioeconómico y de las relaciones jurídicas entre sujetos regidos por el derecho común, siendo ajenas —es decir, quedando fuera de su radio de acción — las actividades bajo el régimen jurídico del servicio público ${ }^{23}$.

En ese sentido, discrepamos de la resolución 182-97-TDC de la Sala de Defensa de la Competencia publicada el 20 de agosto de 2007, correspondiente al caso «Inversiones La Merced S.A.». Se trató de una controversia a raíz de la denuncia de una empresa de servicio de taxi por la imposición de barreras burocráticas que impedían su permanencia en el mercado. La resolución de la Sala confirmó la resolución 03-96CAM/EXP-036 de la Comisión de Acceso al Mercado que declaró inaplicable a la denunciante la exigencia impuesta por la Municipalidad Provincial de Trujillo, establecida en un decreto de alcaldía que obligaba a los taxistas a pintar la carrocería de sus autos de color amarillo cromo, así como sus techos de color negro, debido a que la Municipalidad no justificó la racionalidad de esta exigencia. El análisis de la racionalidad de la disposición municipal contenida en la resolución señalaba lo siguiente:

a. Posición del denunciante: en su denuncia, la Merced cuestionó que se le obligara a pintar sus taxis de color amarillo debido a que ello le impediría continuar usando la presentación que distinguía a sus vehículos dentro del mercado. Asimismo, señaló que dicha medida le generaría sobrecostos, debido a que tendría que repintar vehículos cuya apariencia exterior se encontraba aún en buen estado.

b. Justificación de interés público invocada por la entidad denunciada: la Municipalidad, por su parte, planteó como fundamento de la medida el tema de la seguridad pública, y que esta tenía "como único propósito uniformizar el color de los vehículos que presten el servicio de taxi en el transporte de pasajeros y hacer posible la identificación del vehículo automotor como una medida de seguridad en beneficio de los usuarios frente a las continuas denuncias de asaltos y violaciones que se han presentado contra conductores de vehículos que simulaban prestar servicio de taxi”.

23 El profesor Eduardo Quintana Sánchez en el coloquio desarrollado el 6 de junio de 2013 en la PUCP sostuvo dos observaciones que nos obligan a matizar nuestra posición. La primera se refiere a los procesos de licitación que lleva a cabo el Estado para otorgar la concesión de dichos servicios públicos. Así, en las bases de las licitaciones se pueden establecer condiciones que creen barreras de acceso para que participen determinados postores. En estos casos sostiene que no hay razón para excluir a esas reglas del análisis de las barreras de acceso, pues se trata del acceso al proceso de licitación. La segunda se refiere a la operación comercial de las empresas que ya son titulares de concesiones de servicios públicos. En esta etapa, el concesionario puede ser obligado a cumplir con regulaciones que crean obstáculos para su permanencia en el mercado. A nuestro juicio, la primera es totalmente razonable por encontrarnos en una etapa de selección del concesionario. La segunda puede aceptarse si la nueva regulación impide de manera arbitraria la permanencia del concesionario en el mercado. 
c. Adecuación de la medida adoptada al fin propuesto. Como se ha señalado en el punto III.4 de la resolución, las exigencias que imponen las autoridades administrativas sobre los particulares que realizan actividades económicas elevan los costos de producir y de adquirir bienes y servicios dentro del mercado. Para los consumidores, ello se traduce en precios más altos y, para las empresas, ello genera mayores dificultades para el acceso y la permanencia dentro del mercado.

En este caso, la exigencia impuesta por la Municipalidad genera una serie de sobrecostos que deben ser tomados en cuenta. Con relación a la denunciante, significa tener que volver a pintar sus vehículos y, además, dejar de emplear el color que usualmente lucían los mismos. Así también, para los competidores que buscan diferenciarse dentro de este mercado, produce como efecto que tengan incurrir en mayores costos para poder distinguirse, lo cual ahora será muy difícil, en la medida que todos los taxis tengan el mismo color. Por otro lado, en relación con la justificación de la medida planteada por la Municipalidad, esta Sala considera que no se ha cumplido con justificar por qué y en qué medida el pintado uniforme de los taxis contribuye a reducir las posibilidades de que ocurran asaltos y violaciones. Más aun, cabría la posibilidad de que el pintado uniforme de estos vehículos ocasione mayores dificultades para identificar aquellos vehículos donde se hubieran producido ese tipo de actos delictivos [...].

d. Existencia de opciones menos gravosas: la Sala reconoce que las autoridades municipales se encuentran obligadas a emitir disposiciones que brinden seguridad a los usuarios de los medios de transporte. Sin embargo, la finalidad perseguida por la Municipalidad en este caso podría obtenerse, a un menor costo, a través de medidas tales como, por ejemplo, obligar a los taxistas a iluminar sus placas — que son el elemento que identifica a sus vehículos_ $\mathrm{o}$ a pintar el número de estas en determinadas partes del automóvil, a la vista del usuario.

e. Efectos adversos de la medida: la medida cuestionada perjudica a aquellos agentes económicos que —como la denunciantebuscan distinguirse de sus competidores incorporando ciertos rasgos distintivos o combinaciones de colores en sus vehículos.

El artículo 9o del decreto legislativo 757 establece que toda persona tiene el derecho a organizar y desarrollar sus actividades en la forma que considere conveniente. La libre iniciativa privada en materia de prestación de servicio de transporte bajo la modalidad de taxi, involucra también la utilización de determinados colores o combinaciones de colores en la presentación de las unidades de transporte [...] (cursiva nuestra). 
La resolución 182-97-TDC es muy relevante por haber constituido un precedente de observancia obligatoria sobre los criterios que deberán tenerse en cuenta para determinar la existencia de una barrera burocrática ilegal o irracional que impida el acceso o la permanencia en el mercado. La metodología de análisis fue esquematizada mediante el siguiente flujograma:

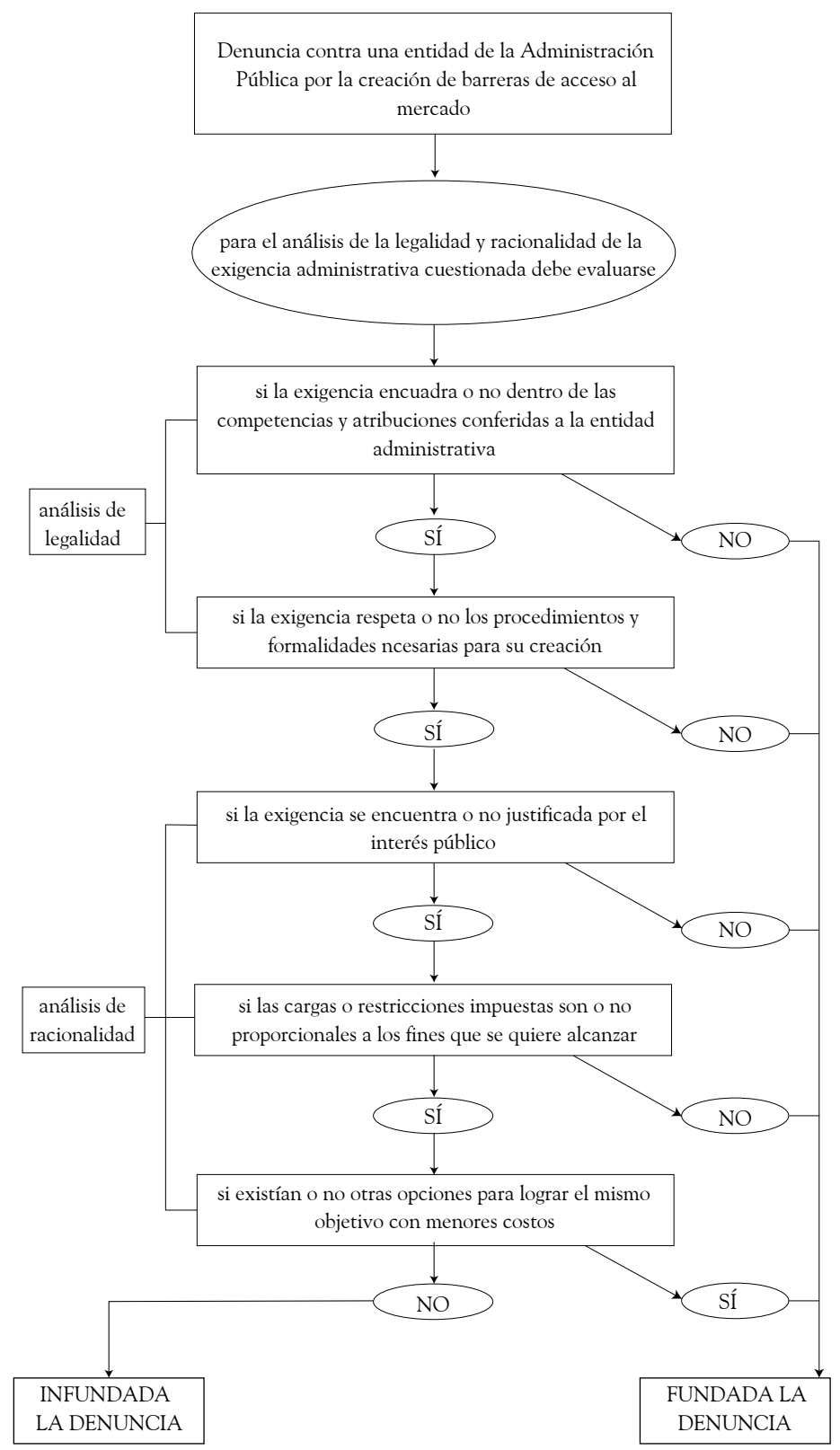


Como se puede apreciar, el test de racionalidad del INDECOPI guarda evidente conexión con el principio de proporcionalidad que posteriormente desarrollóel TribunalConstitucional.Conformealasentenciadel Tribunal Constitucional pronunciada el 21 de septiembre de 2010, recaída en el expediente 0016-2009-PI/TC, sobre proceso de inconstitucionalidad promovido por más de $1 \%$ de ciudadanos del distrito de Pichari contra la Municipalidad de Pichari, el principio de proporcionalidad ha de emplearse a través de sus tres subprincipios: de idoneidad, de necesidad y de proporcionalidad en sentido estricto ${ }^{24}$. Bernal Pulido ${ }^{25}$ señala que el principio de proporcionalidad es un instrumento para controlar la limitación del contenido constitucionalmente protegido de los derechos fundamentales, lo que comprende a su vez tres subprincipios:

(i) El de adecuación o idoneidad. Según este subprincipio, toda intervención en los derechos fundamentales debe ser adecuada para contribuir a la obtención de un fin constitucionalmente legítimo.

(ii) El de necesidad: Según este subprincipio, toda medida de intervención en los derechos fundamentales debe ser la más benigna con el derecho constitucional intervenido, entre todas aquellas que revisten por lo menos la misma idoneidad para alcanzar el objetivo propuesto.

(iii) El de proporcionalidad en sentido estricto. Según este subprincipio, la importancia de la intervención del derecho fundamental debe estar justificada por la importancia del fin perseguido por la intervención legislativa.

Asimismo, el INDECOPI se anticipó a la ley 27444, Ley del Procedimiento Administrativo General, del año 2001, que en el numeral 1.4 del artículo IV del Título Preliminar reconoce como principio general al principio de proporcionalidad pero de manera errónea, ya que lo denomina impropiamente como principio de razonabilidad ${ }^{26}$ :

[...] Principio de razonabilidad.- Las decisiones de la autoridad administrativa, cuando creen obligaciones, califiquen infracciones,

24 RuBio CorReA, Marcial. El test de proporcionalidad en la jurisprudencia del Tribunal Constitucional peruano. Lima: Fondo Editorial de la Pontificia Universidad Católica del Perú, 2011, p. 20. El destacado constitucionalista lo define en los siguientes términos: «El principio de proporcionalidad mide la calidad o cantidad de dos elementos jurídicos (o de elementos con relevancia jurídica) comparativamente entre sí, de manera que haya un exceso de volumen, de significación o de cuantía entre uno y otro, en base a las consideraciones que se hacen en relación a cada tiempo y lugar».

25 Ver: Bernal Pulido, Carlos. Ob. cit.

26 En la obra citada, p. 19, Rubio Correa define al principio de razonabilidad: «[...] exige que los actos que los sujetos realizan frente a los hechos y circunstancias, cumplan el requisito de ser generalmente aceptados por I colectividad como adecuada respuesta a los retos que presenta la realidad al actuar humano jurídicamente relevante. Dichos actos deben estar sostenidos en argumentos de razonamiento objetivos y no subjetivos, en valores y principios aceptados. Debe haber tratamiento imparcial de las personas y, cuando sea pertinente, se debe aplicar la regla de que "donde hay la misma razón, hay el mismo derecho"».

EL CONTROL

DE BARRERAS

BUROCRÁTICAS

POR EL INDECOPI

Y LA TUTELA

DE DERECHOS

FUNDAMENTALES

ECONÓMICOS

INDECOPI'S

BUREAUCRATIC

BARRIERS

CONTROL AND

ECONOMIC

FUNDAMENTAL

RIGHTS

GUARDIANSHIP 
impongan sanciones, o establezcan restricciones a los administrados, deben adaptarse dentro de los límites de la facultad atribuida y manteniendo la debida proporción entre los medios a emplear y los fines públicos que deba tutelar, a fin de que respondan a lo estrictamente necesario para la satisfacción de su cometido.

Sobre la obligación de pintado de amarillo de los taxis por disposición municipal, es relevante la sentencia del Tribunal Constitucional recaída en el expediente 00245-2006-AA, correspondiente al caso «Multiservis Clave 90 E.I.R.L.». En el mencionado proceso se impugnaba una ordenanza de la Municipalidad Provincial de Arequipa por haber establecido para la prestación del servicio de taxi, entre otros requisitos, la obligación del pintado de las unidades en color amarillo. En esta sentencia se declaró infundada la demanda interpuesta con los votos de los magistrados Mesía, Álvarez y Calle. Los magistrados Vergara y Landa votaron por que la demanda sea declarada improcedente. Los magistrados Beaumont y Eto votaron por que se declare fundada la demanda, considerando que el uso de uno u otro color significa un carácter distintivo de la calidad y nivel de servicio que se presta, de modo que restringir tal facultad puede incidir en el éxito de la empresa y su acceso al mercado.

De esta sentencia compartimos el fundamento 4 del voto del magistrado Álvarez Miranda, que resalta la naturaleza de servicio público local del transporte urbano:

Que por otro lado, considero que las disposiciones contenidas en la cuestionada ordenanza no lesionan ninguno de los derechos invocados por la empresa recurrente, en tanto debe tenerse en cuenta que ningún derecho es absoluto, sino que por el contrario, pueden ser limitados, como ocurre en el caso de autos, toda vez que la finalidad que persigue la impugnada norma constituye el ejercicio, por parte de la Municipalidad Provincial de Arequipa, de una competencia constitucionalmente prevista a las autoridades municipales en el artículo 195.8 de la Norma Fundamental, a efectos de desarrollar y regular actividades y/o servicios en materia de transporte colectivo, circulación y tránsito.

Sobre el análisis respecto de si una licencia municipal puede constituir una barrera burocrática, la Sala de Defensa de la Competencia, en la resolución 188-97-TDC de fecha 23 de julio de 2007 recaída a raíz de la denuncia promovida por el Consorcio Panamericano de Inversiones S.A. contra la Municipalidad Distrital de Miraflores, estableció en un precedente de observancia obligatoria los criterios que deberán tenerse en cuenta al momento de evaluar si el cobro de una licencia constituye una barrera burocrática que limita el acceso al mercado, así como las 
cargas en materia probatoria que recaen sobre las partes en estos casos. La precitada resolución 188-97-TDC, al analizar las atribuciones de la Comisión en materia de tasas municipales, señala que los tributos municipales tienen un impacto en las empresas con relación a su permanencia en el mercado:

[...] Sin embargo, también debe tenerse en cuenta que cuando las municipalidades imponen cargas tributarias sobre los particulares que realizan actividades económicas, elevan los costos de producir bienes y servicios en el mercado y encarecen la adquisición de tales productos por parte de los consumidores. Para las empresas, ello se traduce en mayores costos para el acceso y la permanencia en el mercado. Dichos costos, por tanto, deben ser justificados en forma adecuada por los gobiernos locales, de modo tal que su exigibilidad resulte ser natural en razón de las obras y servicios públicos que la ley les encomienda realizar y proveer.

El artículo 61 del Decreto Legislativo 776 señala que las municipalidades no podrán establecer tasas o contribuciones que graven la entrada, salida o el tránsito de personas, bienes, mercaderías, productos y animales en el territorio nacional o que limiten el libre acceso al mercado. En consecuencia, la Comisión tiene la obligación de evaluar si las contribuciones establecidas por los gobiernos locales constituyen o no barreras burocráticas que impiden u obstaculizan el libre acceso y permanencia de los agentes económicos en el mercado, analizando para tal efecto:

a) La legalidad de la tasa o contribución cuestionadas, con la finalidad de determinar si ellas han sido creadas respetando las formalidades y los procedimientos establecidos por las normas aplicables al caso concreto y, asimismo, si encuadran dentro de las atribuciones y competencias conferidas por ley a las municipalidades.

b) La racionalidad de dichos tributos, lo que significa, en el caso específico de las licencias municipales, evaluar si los cobros realizados responden a la prestación efectiva de un servicio público de fiscalización o de control, individualizado en el contribuyente, así como apreciar la racionalidad de los servicios que presta la municipalidad y de los montos que cobra para el financiamiento de dichos servicios.

Asimismo, la Sala de Defensa de la Competencia estableció que las municipalidades tienen la carga de la prueba de que los cobros realizados se derivan a la prestación racional y efectiva de un servicio público de fiscalización o control individualizado en el contribuyente, y que los montos que cobra son racionales. Así, declaró los siguientes principios y reglas como de observancia obligatoria: 
En los casos seguidos ante la Comisión de Acceso al Mercado que se encuentren referidos al cobro de licencias municipales contempladas en el artículo 68, inciso e), del decreto legislativo 776, se deberá tener en cuenta los criterios de interpretación descritos en el esquema que se muestra a continuación.

- El denunciante deberá aportar elementos de juicio razonables acerca de la posible existencia de un cobro ilegal o irracional, por concepto de licencia municipal, que pudiera gravar la entrada, salida o el tránsito de personas, bienes o mercaderías y animales en el territorio nacional o que pudiera restringir el acceso de los agentes económico al mercado.

- La Comisión deberá evaluar la legalidad de la licencia cuyo cobro ha sido impugnado por el denunciante, lo que significa establecer:

a. Si la licencia creada encuadra o no dentro de las atribuciones y competencias conferidas a las municipalidades por su Ley Orgánica y otras normas con rango de ley.

b. Si la licencia fue creada respetando las formalidades y requisitos contenidos en el Código Tributario, en el decreto legislativo 776 y en la Ley Orgánica de Municipalidades.

- La municipalidad, por su parte, tiene la carga de probar que los cobros realizados responden a la prestación racional y efectiva de un servicio público de fiscalización o control individualizado en el contribuyente y, asimismo, que los montos que cobra para financiarlo son racionales. Así, de existir indicios razonables en el sentido que los cobros cuestionados constituyen una barrera burocrática irracional, la Comisión requerirá a la municipalidad denunciada para que acredite lo siguiente:

c. Si la licencia corresponde a la prestación efectiva de un servicio público de fiscalización o control.

d. Si la materia objeto de fiscalización o control guarda coherencia con el interés público definido por la ley e interpretado a través de la licencia.

e. Si la municipalidad ha individualizado adecuadamente a los administrados que se encuentren sujetos al servicio público de fiscalización o control, conforme al mandato de ley.

f. Si existe una razonable equivalencia entre el costo de los servicios de fiscalización o control a los que se refiere la licencia son financiados por otro u otros tributos ya existentes.

- Finalmente, deberá evaluarse si, en base a la información presentada, existen indicios de que los costos de los servicios de fiscalización o control a los que se refiere la licencia son financiados por otro u otros tributos ya existentes. 
En suma, dado que las cargas tributarias establecidas por las municipalidades generan costos para el funcionamiento del mercado, estas corporaciones locales tienen la carga de la prueba sobre los administrados respecto de la legalidad y racionalidad de las licencias que establecen.

\section{III.EL CONCEPTO DE BARRERA BUROCRÁTICA Y EL DERECHO DE IGUALDAD Y NO DISCRIMINACIÓN ECONÓMICA}

La Constitución en su artículo 2, inciso 2, prevé como derecho fundamental de toda persona la igualdad y la prohibición de la discriminación: «Nadie debe ser discriminado por motivo de origen, raza, sexo, idioma, religión u opinión, condición económica o de cualquiera otra índole».

Como se aprecia, se trata de una lista enunciativa y no taxativa ${ }^{27}$. En la Constitución chilena de 1980 se reconoce expresamente la garantía de no discriminación en materia económica en el numeral 22 del artículo 19. Sobre el particular, Evans señala que:

[...] por consiguiente, cualquier intento del Estado, de cualquier organismo o autoridad, aunque ejerza funciones encomendadas por la ley, o del legislador, por imponer gravámenes, restricciones o cargas que no tengan una clara e indiscutible justificación objetiva, fundada en hechos y no en temores o en suspicacias administrativas de connotación subjetiva, constituye una discriminación arbitraria e inconstitucional. Hay implícita, en consecuencia, en el № 22 del art. 19, una limitación a la discrecionalidad administrativa, la que constituye un saludable instituto en un Estado de Derecho ${ }^{28}$.

En el ordenamiento peruano, el artículo 12 del decreto legislativo 757, Ley Marco para el Crecimiento de la Inversión Privada, expedido en noviembre de 1991, previó el principio de no discriminación en materia económica en los siguientes términos.

Artículo 12.- El Estado no establece tratamientos discriminatorios ni diferenciados en materia cambiaria, precios, tarifas o derechos no arancelarios, entre los inversionistas y las empresas en que éstos participen ni basándose en sectores o tipo de actividad económica o en la ubicación geográfica de las empresas. Tampoco podrá establecerlos entre las personas naturales nacionales o extranjeras.

27 HUERTA, Luis. «El derecho a la igualdad: su desarrollo en la Constitución de 1993 y en la jurisprudencia del Tribunal Constitucional del Perú». En Susana Mosquera (coord.). El derecho fundamental de igualdad. Lima: Palestra, 2006, p. 67.

28 EVANS DE LA CuADRA, Enrique. Los derechos constitucionales. Santiago: Editorial Jurídica de Chile, 1999, p. 203. 
Ninguna autoridad, funcionario o empleado del gobierno central, gobiernos regionales o locales en cualesquiera de sus niveles, ni empresas del Estado, podrá establecer o aplicar tratamientos discriminatorios ni diferenciados, de conformidad con lo dispuesto en el presente artículo, bajo responsabilidad.

Este principio de no discriminación económica ha sido invocado y aplicado por el INDECOPI. Así, en un caso en el cual la Municipalidad Distrital de San Borja estableció mediante ordenanza el requisito de contar con una clasificación mínima de cuatro estrellas para el otorgamiento de una licencia de funcionamiento que permita operar con el giro de hospedaje, la Comisión de Eliminación de Barreras Burocráticas declaró en la resolución 0151-2012/CEB-INDECOPI, de 21 de junio de 2012, que tal exigencia era una barrera burocrática e ilegal por vulneración a ese principio, por cuanto:

43. El artículo 12 o del decreto legislativo 757 establece que ninguna autoridad, funcionario o empleado del gobierno central, gobiernos regionales o locales en cualesquiera de sus niveles, ni empresas del Estado, puede establecer o aplicar tratamientos discriminatorios ni diferenciados entre los inversionistas y las empresas en que estos participen basándose en sectores o tipo de actividad económica o en la ubicación geográfica de las empresas.

44. En concordancia con dicha norma, el principio de imparcialidad contemplado en el numeral 1.5을 del artículo IVo de la Ley del Procedimiento Administrativo General, Ley 27444, establece que las autoridades administrativas deben actuar sin ninguna clase de discriminación entre los administrados, otorgándoles tratamiento y tutela igualitaria frente al procedimiento.

45. En el presente caso, la exigencia de contar con 4 estrellas como mínimo, para el otorgamiento de una licencia de funcionamiento que permita operar con el giro de hospedaje, transgrede las normas antes referidas, en la medida que excluye o restringe el acceso al mercado a ciertos proveedores del mercado en función de su condición económica o de la manera en que ofrecen sus servicios, no obstante que puedan cumplir con los estándares mínimos de higiene, seguridad industrial, medio ambiente y la salud.

46. Por tanto, dicha la [sic] exigencia también vulnera lo dispuesto en el artículo $12^{\circ}$ del Decreto Legislativo 757, concordado con el principio de imparcialidad contemplado en el numeral 1.5으 del artículo IVo del Título Preliminar de la Ley 27444.

La Sala de Defensa de la Competencia 1 se ha pronunciado en reiteradas resoluciones sobre el principio de no discriminación en el sentido de que la exigencia del Ministerio de Transportes y Comunicaciones de presentar 
un estudio de factibilidad de mercado financiero y de gestión para prestar el servicio de transporte público regular de personas de ámbito nacional con origen o destino en la provincia de Lima Metropolitana o la provincia constitucional del Callao, materializada en el artículo 39 del Reglamento Nacional de Administración de Transportes, constituye una barrera burocrática ilegal (resoluciones 1221-2011/SC1-INDECOPI, 13612011/SC1-INDECOPI; 1575-2011/SC1-INDECOPI; 1632-2011/SC1; 1451-2011/SC1; 1528-2011/SC1; 1573-2011/SC1-INDECOPI; 1675 2011/SC1; 1011-2012/SC1-INDECOPI; 1012-2012-SC1-INDECOPI; 1126-2012-SC1-INDECOPI y 1127-2012-SC1-INDECOPI).

Así, la Sala de Defensa de la Competencia 1 en la resolución 12212011/SC1-INDECOPI, de fecha 28 de junio de 2011, confirmó la resolución 0186-2010/CEB-INDECOPI, en el extremo que declaró barrera burocrática ilegal la exigencia de presentar el estudio de factibilidad. El fundamento es que la medida cuestionada incumplió los requisitos que establece el artículo 5 de la Ley General de Transporte y Tránsito Terrestre, el artículo 12 de la Ley Marco para el Crecimiento de la Inversión Privada, el artículo IV de la Ley del Procedimiento Administrativo General y el artículo 39 de la mencionada norma de procedimiento.

Con relación al principio-derecho de igualdad, la Sala declaró en los párrafos 74 al 77 que se había configurado lo siguiente:

74. Pese a que la sola vulneración del artículo 5 de la Ley General de Transporte y Tránsito Terrestre es suficiente para declarar barrera burocrática ilegal a la exigencia de presentar un estudio de factibilidad de mercado financiero y de gestión en las rutas que tengan como punto de partida o de llegada las ciudades de Lima y Callao, debe indicarse que la obligación también vulnera el artículo 12 de la Ley Marco para la Inversión Privada y el artículo IV de la Ley del Procedimiento Administrativo General, que prohíben el establecimiento de tratos diferenciados sin razones objetivas de por medio.

75. En efecto, de acuerdo con el artículo 2 de la Constitución Política del Perú, la administración pública no puede tratar de forma distinta a los particulares que se encuentran en la misma situación. Así, según la ley 27444, para que una autoridad exija un requisito adicional a un administrado deberá acreditar que dicho particular se encuentra en una situación distinta que los demás. No basta que la administración pública alegue la existencia de diferencias entre los administrados, pues ello implicaría abrir el camino a posibles arbitrariedades que vulnerarían el derecho fundamental a la no discriminación.

76. Como fue señalado, en el presente caso el MTC no ha acreditado que las empresas de transporte interprovincial que parten o llegan a Lima y/o Callao generan los problemas de sobreoferta de transporte

EL CONTROL

DE BARRERAS

BUROCRÁTICAS

POR EL INDECOPI

y LA TUTELA

DE DERECHOS

FUNDAMENTALES

ECONÓMICOS

INDECOPI'S

BUREAUCRATIC

BARRIERS

CONTROL AND

ECONOMIC

FUNDAMENTAL

RIGHTS

GUARDIANSHIP 
público urbano o deterioro de la infraestructura vial de Lima y/o Callao. En ese sentido, el ministerio no ha demostrado que estos agentes económicos se encuentran en una situación distinta de la del resto de empresas que también brindan servicios de transporte a nivel nacional. No obstante ello, a las primeras empresas les ha exigido la presentación de un estudio de factibilidad y a las segundas no.

77. Considerando que el MTC ha hecho un trato diferenciado entre las empresas que brindan el servicio de transporte terrestre a nivel nacional, sin haber acreditado que un grupo de ellas se encontraba en una situación desigual que ameritase dicha distinción, queda claro que el ministerio ha vulnerado el principio constitucional de igualdad ante la ley recogido en el artículo 12 de la Ley Marco para la Inversión Privada y el artículo IV de la Ley del Procedimiento Administrativo General.

En otro caso relevante, la Sala de Defensa de la Competencia 1, mediante resolución 0026-2012/SC1-INDECOPI del 4 de enero de 2012, confirmó la resolución 0059-2011/CEB-INDECOPI, de la Comisión de Eliminación de Barreras Burocráticas, que declaró fundada la denuncia interpuesta por la Asociación Nacional de Institutos Superiores Tecnológicos Privados (ANISTEP) contra el Ministerio de Educación por la imposición de exigencias relacionadas con el proceso de admisión, materializadas en diversas disposiciones contenidas en las «Normas para la organización y ejecución del proceso de admisión a los institutos y escuelas de educación superior tecnológica», instrumento aprobado mediante resolución ministerial 0025-2010-ED, y posteriormente modificado por la resolución ministerial 0412-2010-ED.

En la precitada resolución, la Sala declaró que dichas disposiciones eran ilegales, dado que fueron establecidas vulnerando el principio de no discriminación previsto en la ley 27444, Ley del Procedimiento Administrativo General y el decreto legislativo 757, Ley Marco para el Crecimiento de la Inversión Privada. Asimismo, determinó que carecen de razonabilidad debido a que la entidad denunciada no presentó evidencias que demuestren que la regulación cuestionada es idónea para satisfacer algún interés en el ámbito educativo, ni que haya sido expedida tras evaluar los diversos costos y beneficios que se generarían con su implementación.

Así, sobre el principio de no discriminación económica, en los párrafos 27 a 29 de la resolución la Sala señaló que el trato diferenciado a favor de los institutos de educación superior en formación técnico profesional de los sectores Defensa e Interior era arbitrario:

27. En el presente caso, pese a que los institutos de educación superior en formación técnico-profesional de los sectores Defensa e Interior y 
los institutos superiores no universitarios habilitados para dar títulos a nombre de la nación son, al igual que los institutos de educación superior tecnológica, centros de formación profesional sujetos a la aplicación de la Ley de Institutos y Escuelas de Educación Superior, se aprecia que la regulación cuestionada u otra similar que fije los parámetros de su organización y ejecución de sus procesos de admisión no les es exigible, estableciéndose así una diferenciación entre sujetos de una misma clase.

28. Como el MINEDU no ha señalado, ni menos aun acreditado, cuáles son los factores objetivos que sustentan esta diferente regulación pese a pertenecer a la misma categoría de centros educativos (institutos de educación superior), se concluye que se está frente a una actuación arbitraria que no ha cumplido con lo exigido por la Ley del Procedimiento Administrativo General y la Ley Marco para el Crecimiento de la Inversión Privada.

29. Por las razones expuestas, la regulación aprobada por el MINEDU —numerales 6.2.7, 6.4.5 y 6.4.6 de la resolución ministerial 0025-2010. ED, así como los artículos 1 y 2 de la resolución ministerial 412-2010. ED_, si bien emitida en el marco de sus competencias, es ilegal por haber vulnerado el principio de no discriminación contemplado en la Constitución y desarrollado por la ley.

Tomás Ramón Fernández, después de citar a Saussure sobre la arbitrariedad de los signos lingüísticos, relaciona el concepto de arbitrariedad con la inexistencia de motivación:

El concepto de arbitrariedad se vincula así en su esencia última al concepto de motivación, de la que los humanos no podemos prescindir en cuanto entes de razón, ni en el plano del logos, que es y no puede dejar de ser el del pensamiento (se piensa con palabras), ni, por supuesto, en el plano del derecho, es decir, del pensamiento y del razonamiento jurídico. El Derecho exige siempre justificación, demanda razones, preserva la razón. Su naturaleza es la de justificar decisiones, actuaciones. Por eso no puede y no podrá nunca rehuir la cuestión del fundamento. Si no se entiende - y se siente- esto, no se entiende nada ${ }^{29}$.

\section{EL CONCEPTO DE BARRERA BUROCRÁTICA Y LA TUTELA DEL DERECHO DE PROPIEDAD EN LA REVOCACIÓN DE LICENCIAS}

Se sostiene que los derechos o intereses legítimos nacidos de un acto administrativo constituyen una propiedad en el sentido constitucional y que la administración pública, excepcionalmente, está facultada a revocarlo. 
Sin perjuicio de ello, en caso de revocación, la administración está obligada a indemnizar. Es lo que se impone por aplicación analógica de las normas constitucionales sobre expropiación ${ }^{30}$. La disposición constitucional que garantiza el derecho de indemnización justipreciada en caso de expropiación está contenida en el artículo 70 de la Constitución Política del Perú, que prevé: «A nadie puede privarse de su propiedad sino, exclusivamente, por causa de seguridad nacional o necesidad pública, declarada por ley, y previo pago en efectivo de indemnización justipreciada que incluya compensación por el eventual perjuicio».

En esa dirección de protección jurídica del derecho de propiedad se sitúa nuestra legislación, que en el artículo 205 de la ley 27444, Ley del Procedimiento Administrativo General, señala:

Cuando la revocación origine perjuicio económico al administrado, la resolución que la decida deberá contemplar lo conveniente para efectuar la indemnización correspondiente en sede administrativa.

A propósito de la revocación de licencias, la Sala de Defensa de la Competencia 1 del INDECOPI, mediante resolución 1535-2010/ SC1-INDECOPI, de fecha 3 de mayo de 2010, confirmó la resolución 0128-2009/CEB-INDECOPI de la Comisión de Eliminación de Barreras Burocráticas, en el extremo que declaró como barrera burocrática ilegal la prohibición de circular vehículos de transporte interprovincial de personas en las zonas «Huaral Damero Histórico» y «Huaral Centro Urbano», establecida en el artículo 14 de la Ordenanza 009-2009-MPH, de la Municipalidad Provincial de Huaral, dado que se consideró que se había revocado de manera indirecta la licencia de la empresa denunciante Empresa de Transportes Turismo Huaral, sin respetar el procedimiento previsto en los artículos 203 y 205 de la Ley del Procedimiento Administrativo General.

Asimismo, la Sala de Defensa de la Competencia 1 aprobó un precedente de observancia obligatoria en los siguientes términos:

a) El desconocimiento de derechos e intereses conferidos por un acto administrativo debe respetar los requisitos para la revocación establecidos en los artículos $203^{31}$ y 205 de la ley 27444, Ley del

30 MARIENHOFF, Miguel. «Revocación del acto administrativo por razones de oportunidad, mérito o conveniencia». La Ley, T. 1980-B, Sec. Doctrina, Buenos Aires, 1980, p. 820. El destacado administrativista argentino sostuvo que: [...] en caso de negativa de la administración a abonar la indemnización, o de disconformidad del administrado con el monto de lo que se le pretende pagar, este último podrá recurrir ante el Poder Judicial en demanda de protección a su derecho. Desde luego, si el administrado se viere constreñido a ocurrir a la justicia, el Estado posiblemente cargará además, con la obligación de pagar los respectivos intereses y eventualmente el importe de la depreciación monetaria».

$31 \mathrm{El}$ artículo 203 de la Ley del Procedimiento Administrativo General establece que los actos administrativos declarativos o constitutivos de derechos o intereses legítimos no pueden ser 
Procedimiento Administrativo General. La omisión de cualquiera de dichos requisitos constituye barrera burocrática ilegal.

b) Constituyen revocaciones indirectas el impedimento o restricción del ejercicio de los derechos e intereses conferidos por un acto administrativo, sin que exista un pronunciamiento expreso desconociendo tales prerrogativas. Todas las revocaciones indirectas son ilegales, porque ello implica que la administración no siguió el procedimiento establecido en los artículos 203 y 205 de la ley 27444.

c) Cuando el cambio de circunstancias que origina la revocación es atribuible al propio administrado, no resulta aplicable el procedimiento de revocación regulado en los artículos 203 y 205 de la ley 27444.

d) En los casos que corresponda otorgar indemnización, esta debe compensar los perjuicios económicos originados hasta la notificación al administrado de la resolución de revocación. Las inversiones efectuadas posteriormente no deben ser contempladas en la resolución de revocación como parte de la indemnización.

e) Cuando se originen perjuicios económicos indemnizables, la resolución de revocación deberá señalar como mínimo la cuantía de la compensación y la autoridad encargada de efectuar el pago. La indemnización se paga de manera integral, en dinero en efectivo, y es exigible a partir de la emisión de la resolución de revocación.

La Sala de Defensa de la Competencia 1 invoca como fundamento constitucional del precedente el concepto de expropiación indirecta y considera a la revocación como una afectación al derecho fundamental de propiedad. Así, en los párrafos 11, 12 y 13 afirma que:

11. Cuando la administración desconoce derechos que anteriormente reconoció a particulares, suele privarlos de su propiedad privada, afectando sus inversiones. La Constitución Política del Perú impone restricciones generales a la privación de propiedad, estableciendo que ninguna persona puede ser privada de su propiedad sino, exclusivamente, por causa de seguridad nacional o necesidad pública, declarada por ley, y previo pago en efectivo de indemnización justipreciada que incluya compensación por el eventual perjuicio.

12. Esta protección fue diseñada específicamente para las expropiaciones tradicionales, pero hoy se admite en el derecho

EL CONTROL

DE BARRERAS

BUROCRÁTICAS

POR EL INDECOPI

Y LA TUTELA

DE DERECHOS

FUNDAMENTALES

ECONÓMICOS

INDECOPI'S

BUREAUCRATIC

BARRIERS

CONTROL AND

ECONOMIC

FUNDAMENTAL

RIGHTS

GUARDIANSHIP 
internacional y en la jurisprudencia extranjera que también alcanza a las denominadas «expropiaciones regulatorias o indirectas». Es decir, a actos gubernamentales que afectan el valor de la propiedad, sin despojar al propietario de su título. Por eso, dicha protección ha sido recogida en los 33 convenios bilaterales de inversión celebrados por el Perú, por el Tribunal Constitucional y defendida por autores nacionales.

13. Esta lógica ha sido trasladada a la ley 27444 , para el caso específico del procedimiento de revocación de los actos administrativos que confieren derechos o intereses a los particulares. Ello debido a que, a través de un procedimiento de revocación, se puede privar parcial o totalmente a los particulares de sus derechos de propiedad (protegidos a través de distintos títulos habilitantes, como por ejemplo licencias de funcionamiento.

Con relación a la jurisprudencia extranjera que se invoca en precitado párrafo 12 , cabe señalar que en el derecho estadounidense se incluye dentro del concepto de takings a otras modalidades de afectación del derecho de propiedad, sin transferencia de dominio al Estado, pero con efecto económico equivalente a la expropiación. En el caso «Penn Central Trasportation Co. vs. City of New York», la Corte Suprema se pronunció el 26 de junio de 1978 acerca de la doctrina de las expropiaciones (takings). La controversia se origina cuando el Comité de Preservación de Estructuras Históricas de la Ciudad de Nueva York declaró a la Terminal Grand Central como edificio histórico. Así, al actor se le negó el permiso para construir un edificio de cincuenta pisos sobre la terminal. Sin embargo, se le permitieron «derechos de construcción transferibles» por los que el accionante podía construir en exceso en ciertos sitios cercanos y «transferibles». Penn demandó a la ciudad de Nueva York con el argumento de que este acto constituía una violación al debido proceso y una expropiación. La Corte asumió el criterio de que la restricción del derecho de construcción no era una expropiación, porque no impedía los usos ya existentes ni un razonable retorno en su inversión. Sin embargo, la opinión de la Corte enfatizaba que la restricción al derecho de construir no debía «frustrar expectativas basadas en inversiones importantes» (frustrate distintictive investment backed expectations $)^{32}$.

Esta doctrina fue modificada en el caso «Lucas vs. South Carolina Coastal Council» (1992), que afirma que si la regulación de la utilización de la propiedad privaba al propietario permanentemente de su explotación económica, se trataba de una expropiación «categorical taking» que debía ser indemnizada. En la sentencia, se comienza el análisis advirtiendo que las apropiaciones físicas y permanentes de tierra 
requieren una compensación justa, «sin importar cuánto peso pueda tener el propósito público detrás de la regulación estatal». David Lucas compró dos lotes de terreno costero no edificados en Carolina del Sur, con el propósito de dedicar uno a inversión inmobiliaria. Antes de que Lucas iniciase cualquier construcción, se aprobó una ordenanza que prohibía toda edificación entre la playa y ciertas líneas de construcción. Lucas reclamaba que la propiedad había sido privada de todo su valor económico. En la sentencia, se sostiene que las apropiaciones físicas y permanentes de tierras requieren una justa compensación económica «sin importar cuánto peso pueda tener el propósito público detrás de la regulación estatal». El fallo —sustentado por el Justice Antonin Scalia - señaló que «existen buenas razones para nuestra creencia frecuentemente expresada de que cuando el propietario de un derecho real debe sacrificar toda utilización económicamente beneficiosa en nombre del bien común, esto, es dejar su propiedad sin uso económico, ha sufrido una expropiación» ${ }^{33}$.

Es relevante destacar que el Tribunal Constitucional, en la sentencia del Expediente 00834-2010-PA/TC, correspondiente al caso «Duke Energy Egenor S. en C. por A.- del EGENOR», ha asumido la doctrina de la expropiación indirecta. Sin embargo, no ha formulado una doctrina jurisprudencial propia, limitándose a invocar en su fundamento 40 el precedente administrativo vinculante recaído en el Expediente 1535-2010/SCI-INDECOPI. Sin negar la legitimidad de la protección del derecho de propiedad en este caso, llama la atención que, existiendo doctrina sobre la expropiación indirecta, el Supremo Tribunal recurra a un precedente administrativo del INDECOPI que solo es vinculante para dicha entidad, a la que no le compete legalmente la interpretación de la Constitución, misión que es competencia del Tribunal Constitucional.

A nuestro juicio, la expropiación indirecta no tiene sustento en nuestro ordenamiento constitucional. Sería conveniente como alternativa que nuestra doctrina y jurisprudencia desarrollen la responsabilidad patrimonial del Estado por actos administrativos ${ }^{34}$. En los hechos, la recepción de la expropiación indirecta debilita la soberanía económica de los Estados receptores de inversión y sus potestades regulatorias en tutela del interés público. Sin embargo, su acogida en nuestro ordenamiento a través de tratados o convenios internacionales es indudable. 


\section{CONCLUSIONES}

La fuerza normativa de la Constitución ha encontrado en la tutela de los derechos económicos fundamentales y en la garantía de la supremacía de la Constitución el fundamento de su institucionalización gracias a la jurisdicción constitucional en sede ordinaria, en sede del Tribunal Constitucional y en sede administrativa de la Comisión de Eliminación de Barreras Burocráticas del INDECOPI.

Sin perjuicio de las discrepancias que en diversos aspectos referidos al servicio público a la expropiación indirecta tenemos con el INDECOPI, debemos reconocer que ha consolidado, a través de sus resoluciones y precedentes, un destacado rol de tutela de los derechos económicos fundamentales.

Ante la inoperancia del sistema judicialista, con jueces y tribunales en lo contencioso administrativo que carecen de una especialización en materias que relacionan el derecho y la economía, consideramos que es hora de debatir una reforma constitucional que reconozca el ejercicio de potestades jurisdiccionales en favor de determinados tribunales administrativos — como los que integran el INDECOPI — en razón de su especialidad. Así, se constituirían en una jurisdicción primaria administrativa solo sujeta a la revisión de sus resoluciones por un tribunal supremo especializado en lo contencioso administrativo - el Consejo de Estado- como en el sistema colombiano ${ }^{35}$. 